\title{
CFD Modelling of Radiation Exposure from Inhalation of Radon Decay Products During Showering
}

\author{
Rabi Rabi ${ }^{1}{ }^{*}$, Lhoucine Oufni ${ }^{1}$, Khamiss Cheikh ${ }^{2}$, El-Houcine Youssoufi ${ }^{1}$, Hamza Badry ${ }^{1}$, \\ Youssef Errami ${ }^{2}$ \\ ${ }^{1}$ Department of Physics (LPM), Faculty of Sciences and Techniques, Sultan Moulay Sliman University, Beni-Mellal, Morocco \\ ${ }^{2}$ Department of Physics (LEIE), Faculty of Sciences, Chouaib Doukkali University, El Jadida, Morocco
}

Email address:

abiismcm@gmail.com (R. Rabi)

${ }^{*}$ Corresponding author

\section{To cite this article:}

Rabi Rabi, Lhoucine Oufni, Khamiss Cheikh, El-Houcine Youssoufi, Hamza Badry, Youssef Errami. CFD Modelling of Radiation Exposure from Inhalation of Radon Decay Products During Showering. Radiation Science and Technology. Vol. 7, No. 1, 2021, pp. 15-20. doi: $10.11648 /$ j.rst.20210701.13

Received: February 25, 2021; Accepted: March 19, 2021; Published: March 26, 2021

\begin{abstract}
Radon is the most harmful natural contaminant in the indoor atmosphere of the buildings. The noble gas, after cigarette smoke, is the biggest cause of lung cancer, and today the study of its diffusion, distribution, and concentration around the world has attracted many researchers in the field of radiation protection and environmental health. Typically, output data obtained from traditional methods of measuring radon concentration in indoor buildings is limited to information on the average radon concentration. Although these data are highly valuable in identifying buildings with a high risk of radon, it can be misleading to identify the real danger for residents of these buildings. This study aims to investigate the effects of water temperature and water flow rate on radon concentration and distribution inside the showers. Numerical simulations were conducted using CFD. Also, radon concentration in water was determined by the radon detector AlphaGUARD and is used as input in CFD simulation. The results showed that variations in the water flow rate have more influence on radon distribution than the changes in water temperature. Experiments were performed by measuring radon concentrations at different times in the shower room using monitor Radon Scout Plus. The annual effective dose of radon concentration in the shower room was also investigated.
\end{abstract}

Keywords: Radon, Temperature, Shower, Computational Fluid Dynamics (CFD), Effective Dose

\section{Introduction}

Radon gas can dissolve and accumulate in water from underground sources (called ground water) [1, 2], such as wells. When water that contains radon is used in the home for showering, washing dishes, and cooking, radon gas escapes from the water and goes into the air [3]. The radon from water contributes to the total inhalation risk associated with radon in indoor air $[4,5]$.

More recently, CFD (Computational Fluid Dynamics) simulation has taken on a distinct place in the study of the behavior of radon in indoor air. Many researchers have predicted the behavior and distribution of radon in buildings, apartments, offices, and schools, using CFD simulations [610]. But, a major limitation of these studies is not taking into account the influence the exhalation of radon from the water.
In this study, CFD simulations were carried out to predict the behavior of radon concentration in the shower room and to estimate the effects of water temperature and the water flow rate on radon concentration during the showering process. The results from this study will hopefully contribute to a better understanding of the problem of radon release from water, and provide data to permit a more accurate calculation of the dose derived from domestic use of water.

\section{The Numerical Method}

\subsection{Physical Model}

The shower and manikin are modelled with a CFD software package for predicting the behavior of radon concentration in the shower room. The CFD model of the shower and the position of manikin in the shower are shown 
in Figure 1. The size of the shower is $(1 \mathrm{~m} \times 1 \mathrm{~m} \times 2 \mathrm{~m})$, as well as the manikin had the standard height $(1.70 \mathrm{~m})$, and the total surface area $\left(1.81 \mathrm{~m}^{2}\right)$. A shower head consisting of 9 orifices of 4-mm diameter was located in the center of the shower room, normally at a height of $1.70 \mathrm{~m}$ from the floor.

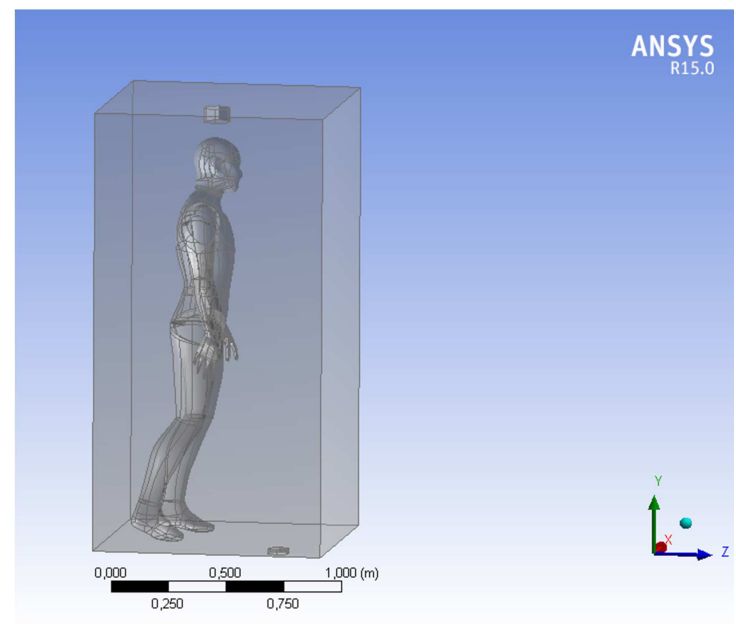

Figure 1. Geometrical of the shower model and position of the manikin.

\subsection{The Numerical Approach}

The air flow (Air-water) in the shower room was assumed to be Newtonian and incompressible fluid in turbulent regime. Under these considerations, the unsteady governing equations for mixed convection inside a shower are mass, momentum, temperature and radon concentration $\left({ }^{222} \mathrm{Rn}\right)$ conservation equations, written as $[11,12]$ :

$$
\begin{gathered}
\frac{\partial\left(\rho \mathrm{U}_{\mathrm{i}}\right)}{\partial \mathrm{X}_{\mathrm{i}}}=0 \\
\frac{\partial\left(\rho \mathrm{U}_{\mathrm{i}}\right)}{\partial \mathrm{t}}+\frac{\partial\left(\rho \mathrm{U}_{\mathrm{i}} \mathrm{U}_{\mathrm{j}}\right)}{\partial \mathrm{X}_{\mathrm{i}}}=-\frac{\partial \mathrm{P}}{\partial \mathrm{X}_{\mathrm{i}}}+\frac{\partial}{\partial \mathrm{X}_{\mathrm{i}}}\left[\mu\left(\frac{\partial \mathrm{U}_{\mathrm{i}}}{\partial \mathrm{X}_{\mathrm{i}}}+\frac{\partial \mathrm{U}_{\mathrm{j}}}{\partial \mathrm{X}_{\mathrm{i}}}\right)\right]+\rho \mathrm{g} \\
\frac{\partial \mathrm{T}}{\partial \mathrm{t}}+\frac{\partial\left(\mathrm{U}_{\mathrm{i}} \mathrm{T}\right)}{\partial \mathrm{X}_{\mathrm{i}}}=\alpha \frac{\partial^{2} \mathrm{~T}}{\partial \mathrm{X}_{\mathrm{i}}{ }^{2}}
\end{gathered}
$$

where, $\mathrm{X}$ is the coordinate axis in the direction $(\mathrm{i}=1,2,3), \mathrm{U}_{\mathrm{i}}$ corresponds to the mean velocity $\left(\mathrm{m} \mathrm{s}^{-1}\right)$ in the $\mathrm{i}$ direction, and $\rho$ is mixture density (Air- $\left.{ }^{222} \mathrm{Rn}\right)\left(\mathrm{Kg} \mathrm{m}^{-3}\right)$. Here $\mathrm{P}$ is pressure $\left(\mathrm{N} \mathrm{m}^{-2}\right), \mu$ is the molecular viscosity $\left(\mathrm{N} \mathrm{s} \mathrm{m}^{-2}\right)$, $\alpha$ thermal diffusivity $\left(\mathrm{m}^{2} \mathrm{~s}^{-1}\right)$ and $\mathrm{g}$ is the gravitational acceleration $\left(\mathrm{m}^{2} \mathrm{~s}^{-1}\right)$.

Dispersion of radon gas inside the shower was simulated using equation [12]:

$$
\frac{\partial \mathrm{C}}{\partial \mathrm{t}}+\frac{\partial\left(\mathrm{U}_{\mathrm{i}} \mathrm{C}\right)}{\partial \mathrm{X}_{\mathrm{i}}}=\mathrm{D} \frac{\partial^{2} \mathrm{C}}{\partial \mathrm{X}_{\mathrm{i}}^{2}}-\lambda \mathrm{C}
$$

where: $\mathrm{u}, \mathrm{v}$ and $\mathrm{w}$ are the velocity components, $\mathrm{x}, \mathrm{y}$ and $\mathrm{z}$ are the Cartesian coordinates used, $\mathrm{T}$ is the temperature, $\mathrm{p}$ is the pressure, $\alpha$ is the thermal diffusivity, $C_{j}$ is the concentration of radon, $\mathrm{D}$ is the diffusion coefficient, and $\lambda$ is the decay constant of radon.

\subsection{Numerical Solution and Boundary Conditions}

In this study, Fluent 6.2 software has been utilized to solve the set of equations introduced in the previous section. In numerical solution, the SIMPLE algorithm was used to correct the pressure-velocity decoupling and second order discretization method was applied for convection terms [13].

In the solution process, meshing is very important for the verification, stability and precision of the results. Unstructured grids are useful for complex geometries thus, tetrahedral elements were chosen for grid generation. Mesh structure of the surfaces of the manikin and the shower are shown in Figure 2. Computational model consists of $1,500,000$ tetrahedral elements. The convergence is supposed when the residuals of the energy and the radon concentration equations are less than $10^{-4}$.

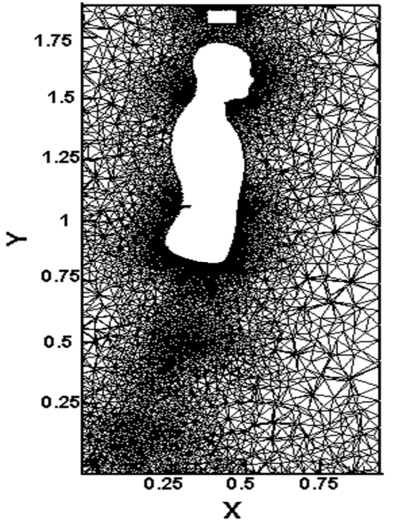

Figure 2. The mesh structure of the shower.

Table 1 shows the boundary conditions in detail for the surfaces of the shower and the manikin as well as to the inlet and outlet openings. It should be noted that the water inlet is taken as a source of radon in the shower room. Therefore, an experiment was realized to measure the radon concentration level in water using the radon detector AlphaGUARD [14].

Table 1. Boundary conditions.

\begin{tabular}{ll}
\hline Location & Boundary condition \\
\hline Inflow boundary & $\mathrm{U}=\mathrm{W}=0 ; \mathrm{V}=\mathrm{V}_{\text {inlet }} ; \mathrm{T}=\mathrm{T}_{\text {inlet }} ; \mathrm{C}=\mathrm{C}_{\text {inlet }}$ \\
Outflow boundary & $\frac{\partial(\mathrm{U}, \mathrm{V}, \mathrm{W}, \mathrm{T}, \mathrm{C})}{\partial \mathrm{Y}}=0$ \\
Walls & $\mathrm{U}=\mathrm{V}=\mathrm{W}=\mathrm{C}=0, \frac{\partial \mathrm{T}}{\partial \mathrm{X}}=\frac{\partial \mathrm{T}}{\partial \mathrm{Y}}=\frac{\partial \mathrm{T}}{\partial \mathrm{z}}=0$ \\
Surface manikin & $\mathrm{U}=\mathrm{V}=\mathrm{W}=\mathrm{C}=0 \mathrm{~T}=306 \mathrm{k}$ \\
\hline
\end{tabular}

\section{Determination of Radon Concentration in Water}

The radon concentration in the water samples was measured with AlphaGUARD PQ2000 (Genitron Instruments, GmbH, Germany). All water samples were carefully collected to prevent escape of the radon gas from samples. Water was allowed to run for $5 \mathrm{~min}$, and then a $20 \mathrm{ml}$ sample was taken using vessels connected to detector through the pump.

For the determination of radon concentration in water samples, the following equation was used [14]: 


$$
\mathrm{C}_{\text {water }}=\frac{\mathrm{C}_{\text {air }}\left(\frac{\mathrm{V}_{\text {system }}-\mathrm{V}_{\text {sample }}}{\mathrm{V}_{\text {sample }}}-\mathrm{k}\right)}{1000}
$$

where $\mathrm{C}_{\text {water }}$ is the radon concentration in the sample of tap water $\left(\mathrm{Bq} \mathrm{L} \mathrm{L}^{-1}\right), \mathrm{C}_{\mathrm{air}}$ is radon concentration indicated by AlphaGUARD (Bq $\left.\mathrm{m}^{-3}\right), \mathrm{V}_{\text {system }}$ is the volume of the measurement set-up $(\mathrm{mL}), \mathrm{V}_{\text {sample }}$ is the volume of the water sample $(\mathrm{mL})$ and $\mathrm{k}$ is the diffusion coefficient for radon in water. This was determined from equation (6) [14]:

$$
k=0.106+0.405 \mathrm{e}^{-0.052 \mathrm{~T}}
$$

where, $\mathrm{k}$ is the diffusion coefficient of radon; $\mathrm{T}$ is the temperature of water $\left({ }^{\circ} \mathrm{C}\right)$.

\section{Results and Discussion}

The radon concentrations in water samples were measured

(a)

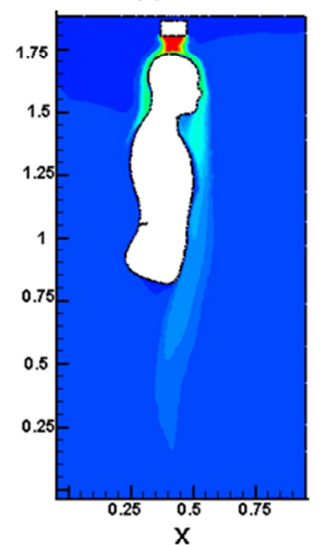

(b)

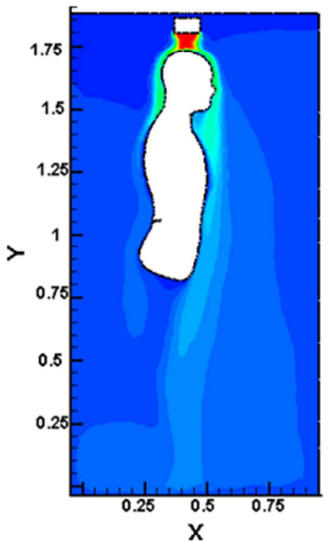

(c)

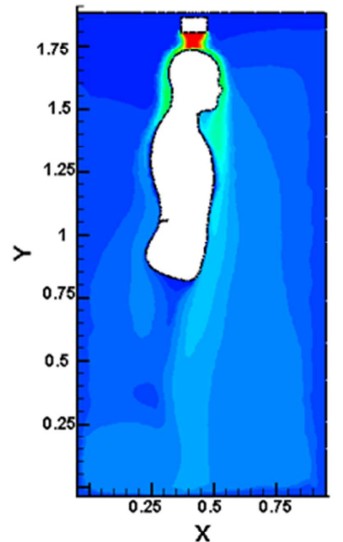

using AlphaGUARD are given in Table 2. The average radon concentration in the water samples is $10.61 \mathrm{~Bq} \mathrm{~L}^{-1}$. This average value of radon concentration in water is used the key input for simulation; the CFD model was developed for radon dispersion study in shower model.

Table 2. Radon concentration in water obtained from experiments in various zones of Beni-Mellal.

\begin{tabular}{ll}
\hline Water sample & $\mathbf{A}_{\mathbf{c}}\left({ }^{\mathbf{2 2 2}} \mathbf{R n}\right)\left(\mathbf{B q ~ L}^{\mathbf{- 1}}\right)$ \\
\hline BM1 & 10.54 \\
BM2 & 10.47 \\
BM3 & 10.61 \\
BM4 & 10.84 \\
\hline
\end{tabular}

\subsection{Radon Distribution}

Distribution of radon concentrations at different time interval are shown in Figure 3. In this case, the water flow rate and the temperature are set at $0.2 \mathrm{~L} \mathrm{~s}^{-1}$ and $25^{\circ} \mathrm{C}$ respectively.

(c) (d)

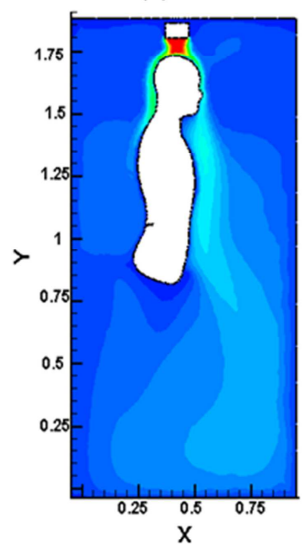

(e)

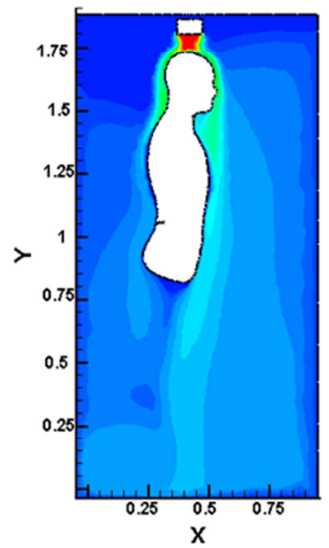

\section{$\begin{array}{llllllllll} & & & & & & & & & \end{array}$}

Figure 3. Contours of radon concentration (Bq $\left.\mathrm{m}^{-3}\right)$ at various times, in the studied shower at plane $(\mathrm{Z}=0.5 \mathrm{~m})$. (a $\left.t=5 \mathrm{~min}\right)$, (b t=10 $\left.\mathrm{min}\right)$, (c $\left.t=20 \mathrm{~min}\right)$, (d $t=30 \mathrm{~min})$ and $(e \mathrm{t}=5 \mathrm{~min})$.

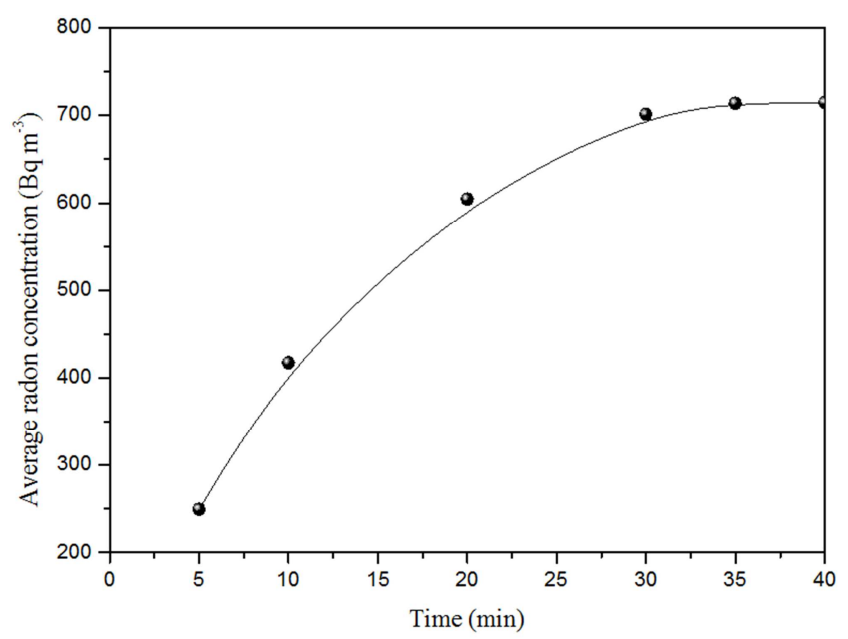

Figure 4. Average radon concentration $\left(B q \mathrm{~m}^{-3}\right)$ for various times with $T=20^{\circ} \mathrm{C}$ and $V=0.2 \mathrm{Ls}^{-1}$.

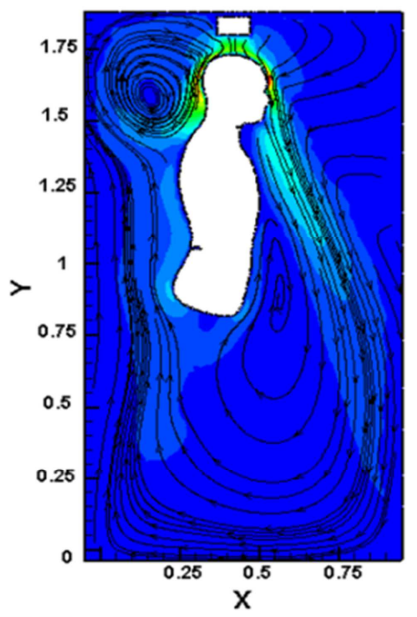

$0.07 \quad 0.220 .36 \quad 0.500 .650 .790 .941 .08$

Figure 5. Air velocity $\left(\mathrm{m} \mathrm{s}^{-1}\right)$ in the studied shower at plane $(\mathrm{Z}=0.5 \mathrm{~m})$. 
During early times, it can be seen the radon concentrations high near shower heads and the lowest values are close to the floor, with the passage of time the radon concentration dispersed rapidly into the shower environment, and reaches the equilibrium state from $30 \mathrm{~min}$ (Figure 4). However, the no-uniformity observed in spatial distribution of radon due to the air velocity profile as shown in Figure 5.

\subsection{Effects of the Water Flow Rate on the Radon Concentration in the Shower Room}

In order to investigate the effect of water flow rate on the radon concentration in the shower room, six values of water flow rate were chosen: $0.1 \mathrm{~L} \mathrm{~s}^{-1}, 0.15 \mathrm{~L} \mathrm{~s}^{-1}, 0.2 \mathrm{~L} \mathrm{~s}^{-1}, 0.25 \mathrm{~L} \mathrm{~s}^{-1}$,
$0.3 \mathrm{~L} \mathrm{~s}^{-1}$, and $0.35 \mathrm{~L} \mathrm{~s}^{-1}$. In these cases, the temperature and the time are set at $25^{\circ} \mathrm{C}$ and $30 \mathrm{~min}$ respectively. The results of the simulation are shown in Table 3.

Figure 6 indicates the effect of varying water flow rate on the radon concentration in the shower room. We observe that the radon concentration increases with increase the water flow. This may be because the more water flow rate in the shower increase, more radon is transferred from water to air during a shower run. Indeed, when water issues from a nozzle into the air, it may form a jet that will later break up into drops, or it may come out already in the form of drops, and therefore, more the velocity of the jet increase, the more surface area of water that comes into contact with the surrounding air increases.

Table 3. Average radon concentration $\left(\mathrm{Bq} \mathrm{m}^{-3}\right)$ obtained from $\mathrm{CFD}$ simulation for various water flow rate with $\mathrm{T}=20^{\circ} \mathrm{C}$

\begin{tabular}{llllll}
\hline Water flow rate $\left(\mathbf{L ~ s}^{-1}\right)$ & $\mathbf{0 . 1 0}$ & $\mathbf{0 . 1 5}$ & $\mathbf{0 . 2 0}$ & $\mathbf{0 . 2 5}$ & $\mathbf{0 . 3 0}$ \\
\hline Average concentration of radon $\left(\mathrm{Bq} \mathrm{m}^{-3}\right)$ & 385.66 & 502.27 & 714.84 & 779.18 & 847.91 \\
\hline
\end{tabular}

(a)

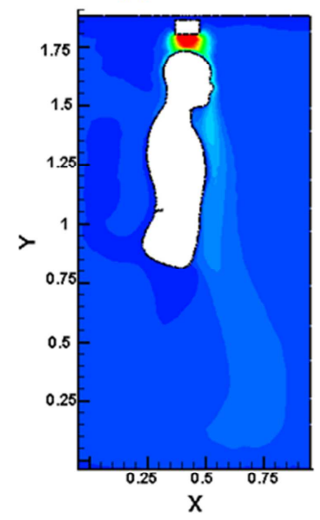

(b)

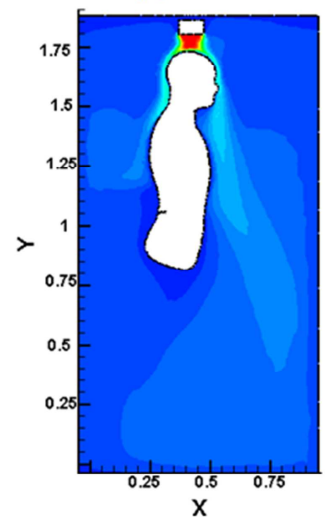

(c)

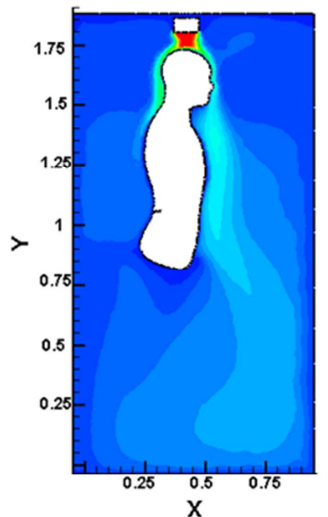

(d)

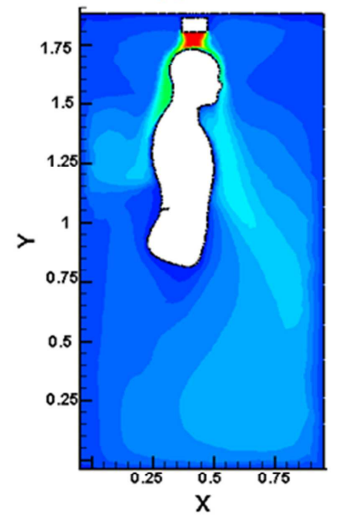

(e)

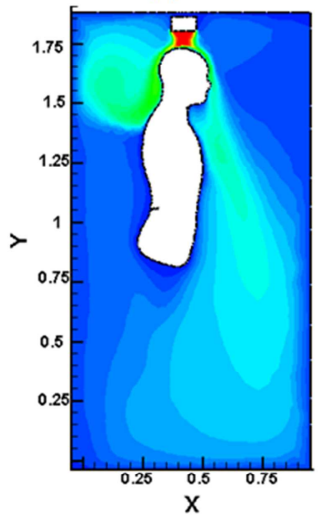

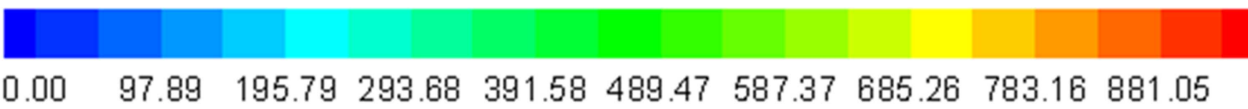

Figure 6. Contours of radon concentration $\left(B q \mathrm{~m}^{-3}\right)$ as a function of water flow rate, in the studied shower at plane $(\mathrm{Z}=0.5 \mathrm{~m})$. (a $\left.\mathrm{V}=0.1 \mathrm{~L} \mathrm{~s}^{-1}\right)$, (b $\mathrm{V}=0.15 \mathrm{~L} \mathrm{~s}^{-}$ $\left.{ }^{1}\right),\left(c V=0.2 L s^{-1}\right),\left(d V=0.25 L s^{-1}\right)$ and $\left(e V=0.35 L s^{-1}\right)$.

\subsection{Effects of the Water Temperature on the Radon Concentration in the Shower Room}

Five cases are considered so as to investigate the impact of temperature changes on radon level in the shower room. The temperature values are $20,25,30,35$ and $40^{\circ} \mathrm{C}$. In these cases, water flow and also the time are set at $0.2 \mathrm{~L} \mathrm{~s}^{-1}$ and 30 min respectively.

Figure 7 shows the effect of temperature on the radon concentration in the shower room, by comparing these figures, it can be seen that the radon concentration in shower decreases when the temperature of water increases. This may be due to the fact that, the radon is soluble in water, and its solubility decreases rapidly with temperature [14]. The average values of radon concentration in this case are summarized in Table 4. The minimum and maximum values for the radon in the shower room were $897.67 \mathrm{~Bq} \mathrm{~m}^{-3}$ for water at $20^{\circ} \mathrm{C}$, and $418.59 \mathrm{~Bq} \mathrm{~m}^{-3}$ for water at $40^{\circ} \mathrm{C}$.

Table 4. Average radon concentration $\left(B \mathrm{~m}^{-3}\right.$ ) obtained from CFD simulation for various temperatures with $V=0.2 \mathrm{Ls}^{-1}$.

\begin{tabular}{llllll}
\hline Temperatures of water $\left({ }^{\circ} \mathbf{C}\right)$ & $\mathbf{2 0}$ & $\mathbf{2 5}$ & $\mathbf{3 0}$ & $\mathbf{3 5}$ & $\mathbf{4 0}$ \\
\hline Average concentration of radon $\left(\mathrm{Bq} \mathrm{m}^{-3}\right)$ & 897.67 & 714.84 & 709.15 & 688.76 & 418.59 \\
\hline
\end{tabular}


(a)

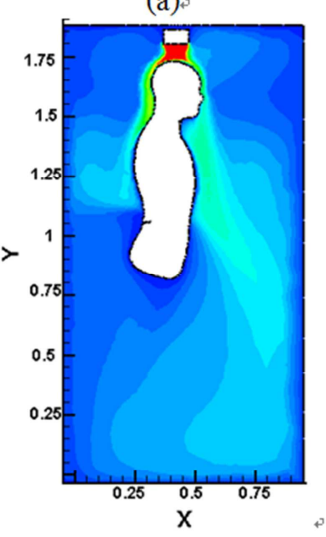

(b)

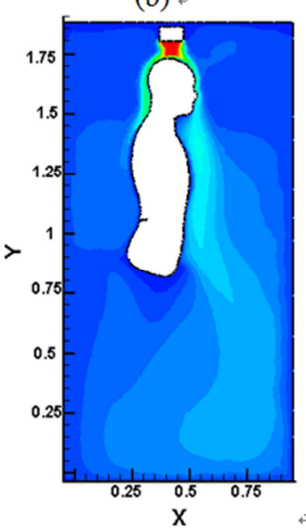

(c)

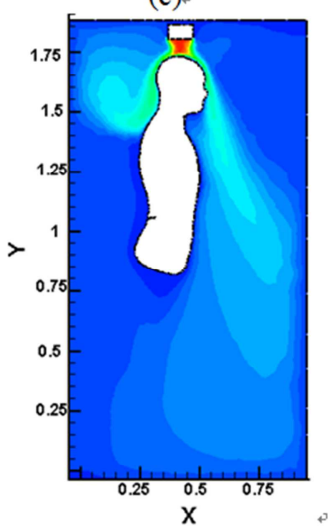

(d)

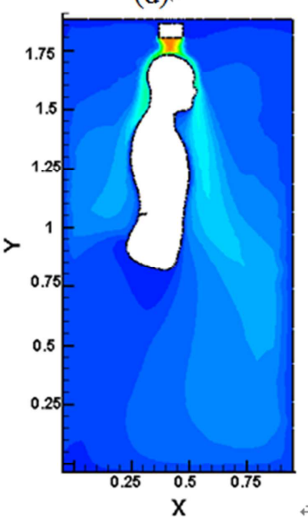

(e)

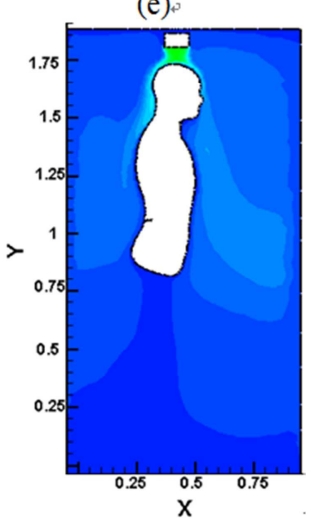

\section{$0.00 \quad 97.89 \quad 195.79293 .68 \quad 391.58 \quad 489.47 \quad 587.37 \quad 685.26 \quad 783.16 \quad 881.05$}

Figure 7. Contours of radon concentration $\left(B q \mathrm{~m}^{-3}\right)$ as a function of water temperature, in the studied shower at plane $(\mathrm{Z}=0.5 \mathrm{~m}) .\left(\mathrm{a} T=20^{\circ} \mathrm{C}\right),\left(\mathrm{b} T=25^{\circ} \mathrm{C}\right),(\mathrm{c}$ $\left.T=30^{\circ} \mathrm{C}\right),\left(d T=35^{\circ} \mathrm{C}\right)$ and $\left(e \mathrm{~T}=40^{\circ} \mathrm{C}\right)$.

\subsection{Experimental Results}

In order to allow a comparison with the experimental results, Radon Scout Plus (SARAD, GmbH, Dresden, Germany) [15] monitor was used for the measurement of radon concentrations in the shower room. For the ${ }^{222} \mathrm{Rn}$ measurements, the detector was placed at $1.50 \mathrm{~m}$ above ground as representative of breath height inside the shower, and the shower was operated at a water flow rate of $0.2 \mathrm{~L} \mathrm{~s}^{-1}$ at a temperature of $22^{\circ} \mathrm{C}$. The results of measurement are shown in Table 5. Overall, the results of the simulation were much closer to the experimental results, whose the maximum difference between them was less than $6.95 \%$. Therefore, it seems that the CFD procedures employed in the present study can produce good predictions of the characteristics of the water flow and the consequent indoor radon concentration for the primary calculation.

\subsection{Estimation of Annual Effective Dose}

The annual effective dose ( $\mathrm{mSv} \mathrm{y}^{-1} \mathrm{~min}^{-1}$ of exposure) due to the radon progeny to the members of the public was also estimated according to the following formula [16]:

$$
\mathrm{E}=\mathrm{A}_{\mathrm{c}}\left({ }^{222} \mathrm{Rn}\right) \mathrm{F} \text { t D }
$$

where $A_{c}\left({ }^{222} R n\right)$ is the radon activity or radon concentration in the shower air $\left(\mathrm{Bq} \mathrm{m} \mathrm{m}^{-3}\right), \mathrm{F}=0.4$ is the equilibrium factor between radon and its progeny in shower air, $\mathrm{t}=1 \mathrm{~min} \mathrm{y}^{-1}$ and $\mathrm{D}=5.410^{-4} \mathrm{mSv}\left(\mathrm{Bq} / \mathrm{m}^{3} \mathrm{~min}\right)^{-1}$ is the dose conversion factor [16].

Table 5. Comparison of CFD simulation results with experimental measurement and Annual effective doses (AED) calculated at various time in the shower model.

\begin{tabular}{|c|c|c|c|c|}
\hline \multirow{2}{*}{ Time } & \multicolumn{2}{|c|}{ Radon concentration $\left(\mathrm{Bq}^{-3}\right)$} & \multirow{2}{*}{ Relative deviation (\%) } & \multirow{2}{*}{ Effective dose $\left(\mathrm{mSv} \mathrm{y}^{-1} \mathrm{~min}^{-1}\right.$ of exposure) } \\
\hline & CFD Simulation & Experimental measurement & & \\
\hline $10 \mathrm{~min}$ & 417.27 & 398.00 & 4.61 & 0.90 \\
\hline $20 \mathrm{~min}$ & 620.54 & 584.00 & 3.39 & 1.95 \\
\hline $30 \mathrm{~min}$ & 701.18 & 675.00 & 3.73 & 4.54 \\
\hline $40 \mathrm{~min}$ & 714.80 & 680.00 & 4.86 & 6.17 \\
\hline
\end{tabular}

Relative deviation $=(\mid$ Measurement- CFD prediction $\mid) /$ CFD prediction

Table 5 shows data obtained for the annual effective dose received by an individual during the showering process. We note that the annual effective doses increase with the shower time. This is due to the fact that the exposure time and radon concentration are very important in the worst-case. The values of effective dose found within the present study are less than ICRP [17] recommended limit of 3-10 $\mathrm{mSv} \mathrm{y}^{-1}$.

\section{Conclusions}

We have studied numerically using CFD simulation the effects of water temperature and the water flow rate on the distribution of radon concentration during showering. The results showed that the more water flow rate in the shower increase, the more radon is transferred from water to air during a shower run; were also found that the radon concentration in the shower decreases when the temperature of water increases. The simulation results of radon concentration were compared with measuring results at different times in the shower using Radon Scout Plus monitor. From the simulation, we calculated the effective dose received by an individual during the showering process. 


\section{References}

[1] Thuamthansanga T, Sahoo BK, Tiwari RC, Sapra BK. A study on the anomalous behaviour of Radon in different depths of soil at a tectonic fault and its comparison with time-series data at a distant continuous monitoring station. SN Applied Sciences. 2019; 1: 683 .

[2] Ouabi H. Modeling of radon and its short-lived decay products emanating from tap water used inside a house: dose to adult members of the public. Appl Radiat Isot. 2009; 67: 115-121.

[3] Barberio MD, Gori F, Barbieri M, Billi A, F Casalati, Franchini S, Lorenzetti L, Petitta M. Optimization of dissolved Radon monitoring in groundwater to contribute to the evaluation of the seismic activity: an experience in centralsouthern Italy. SN Applied Sciences. 2020; 2: 1392

[4] Oufni L, Misdaq MA, Amrane M. Radon level and radon effective dose rate determination in Moroccan dwellings using SSNTDs. Radiat Measur. 2005; 40: 118.

[5] Matthew Omoniyi Isinkaye, Yinka Ajiboye. Correlations of ${ }^{226} \mathrm{Ra}$ and ${ }^{222} \mathrm{Rn}$ activity concentrations in surface soil and groundwater of basement complex geological area of southwest Nigeria. SN Applied Sciences. 2020; 2: 1008.

[6] Zhou W, Iida T, Moriizumi J, Aoyagi T, Takahashi I. Simulation of the Concentrations and Distributions of Indoor Radon and Thoron. Radiat Prot Dosimetry. 2001; 93: 357-367.

[7] Akbari K, Mahmoudi J, Ghanbari M. Influence of indoor air conditions on radon concentration in a detached house. J Environ Radioact. 2013; 116: 166.

[8] Rabi R, Oufni L. A theoretical investigation of the distribution of indoor radon concentrations. Indian J Phys. 2017; 91: 471479 .
[9] Chauhan N, Chauhan RP, Joshi M, Agarwal TK, Aggarwal P, Sahoo BK. Study of indoor radon distribution using measurements and CFD modeling. J Environ Radioact. 2014; 136: $105-111$.

[10] de With G, de Jong P. CFD modelling of thoron and thoron progeny in the indoor environment. Radiat Prot Dosimetry. 2011; 145: 138-144.

[11] Rabi R, Oufni L. Study of radon dispersion in typical dwelling using CFD modeling combined with passive-active measurements. Radiat Phys Chem. 2017; 139: 40-48.

[12] Agarwal TK, Joshi M, Sahoo BK, Kanse SD, Sapra BK. Effect of ${ }^{220} \mathrm{Rn}$ gas concentration distribution on its transmission from a delay chamber: evolving a CFD-based uniformity index. Radiat Prot Dosimetry. 2016; 168: 546-552.

[13] Agarwal TK, Sahoo BK, Gaware JJ, Joshi M, Sapra BK. CFD based simulation of thoron $\left({ }^{220} \mathrm{Rn}\right)$ concentration in a delay chamber for mitigation application. J Environ Radio. 2014; 136: 16-21.

[14] Correa JN, Paschuk SA, Schelin HR, Barbosa L, Sadula T, Matsuzaki CA Measurements of radon concentraon level in drinking water at urban area of Criba (Brazil). Internaonal Nuclear Atlanc Conference INAC. 2009, Rio.

[15] Rabi R, Oufni L. A theoretical and experimental investigation of spatial distribution of radon in a typical ventilated room. MAPAN-Journal of Metrology Society of India. 2018; 33: 123-130.

[16] United Nations Scientific Committee on the Effects of Atomic Radiation (UNSCEAR), 2000. Sources and Effects of Ionising Radiation, vol. I. Annex B. United Nations, New York.

[17] International Commission on Radiological Protection, Proceedings of the Third International Symposium on the System of Radiological Protection. Annals of the ICRP. 2016; $45,1 \mathrm{~S}$. 